\title{
Experimental investigation of flow pulsation waveforms in rectangular mesochannels for high heat flux electronics cooling
}

\author{
Jaakko McEvoy \\ Trinity College Dublin, Ireland, jmcevoy@tcd.ie
}

\section{SAJAD ALIMOHAMMADI}

Technological University Dublin, sajad.alimohammadi@tudublin.ie

Tim Persoons

Trinity College Dublin, Department of Mechanical and Manufacturing Engineering, Dublin, Ireland

Follow this and additional works at: https://arrow.tudublin.ie/engschmecart

Part of the Mechanical Engineering Commons

\section{Recommended Citation}

McEvoy, J., Alimohammadi, A. \& Persoons, T. (2021). Experimental investigation of flow pulsation waveforms in rectangular mesochannels for high heat flux electronics cooling. Experimental Thermal and Fluid Science, vol. 109, December 2019, 109885. doi:10.1016/j.expthermflusci.2019.109885

This Article is brought to you for free and open access by the School of Mechanical and Design Engineering at ARROW@TU Dublin. It has been accepted for inclusion in Articles by an authorized administrator of ARROW@TU Dublin. For more information, please contact arrow.admin@tudublin.ie, aisling.coyne@tudublin.ie, gerard.connolly@tudublin.ie.

Funder: Science Foundation Ireland (SFI); Irish Research Council (IRC)

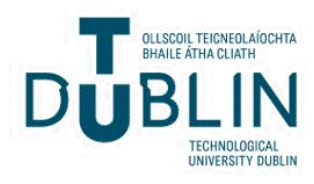




\title{
Manuscript Details
}

\section{Manuscript number}

Title
ETFS_2018_1688_R2

Experimental investigation of flow pulsation waveforms in rectangular mesochannels for high heat flux electronics cooling

\section{Article type}

Research Paper

\begin{abstract}
The ever rising heat fluxes encountered in electronic devices present a challenging thermal engineering problem. Not only is heat transfer enhancement a goal but more recently control of the enhancement is desired, especially in large scale data facilities where the heated outlet coolant fluid may be of use. Flow pulsation is one of the most common active heat transfer enhancement methods studied across all heat sink sizes. While the effects of pulsation have been shown to increase heat transfer under certain conditions there is still disagreement upon its merit for practical applications, with the majority of previous research has been limited to only sinusoidally oscillating flows. In this work the effect of symmetric and asymmetric excitation waveforms on heat transfer with single phase pulsatile fluid flow in mesochannels is investigated through micro particle image velocimetry ( $\mu$-PIV) and a thermal test rig. The channel measures $25 \mathrm{~mm}, 0.58 \mathrm{~mm}$ and $1.15 \mathrm{~mm}$ in length, width and height respectively, giving a hydraulic diameter $(\mathrm{Dh})=$ $771 \mu \mathrm{m}$. A $\mu$-PIV stage with a Nikon 10x/0.3 objective coupled to a double pulsed Nd:YLF high-speed laser and CMOS camera (1024×1024 pixels, 12 bit) were used for recording PIV images. The ability to operate both the camera and light source at high speeds $(500 \mathrm{fps} / \mathrm{Hz})$ allowed for the discretization of the flow velocity over one cycle to calculate the fluctuating velocity components. For a constant Reynolds number of 150 , a range of excitation frequencies were studied $(1 \mathrm{~Hz}, 5 \mathrm{~Hz}, 16.55 \mathrm{~Hz}, 25 \mathrm{~Hz})$ to give Womersley numbers of; $1,2.24,4.1,5$ respectively. To study the effect of altering excitation waveforms on heat transfer in mesochannels a high power density heater cartridge was placed below the test channel, with 5 thermocouples placed evenly along the entire channel length. The use of asymmetric excitation waveforms were found to generate significantly larger fluctuating velocity components in streamwise direction over symmetric waveforms. For cases with large asymmetric fluctuations the temperature of the 5 channel probes was found to be notably lower for a same heating power, indicating an enhancement in heat transfer. The best enhancement in heat transfer was found to be for an asymmetric waveform (F_1), with a $28 \%$ increase over standard steady flow. This simple method of altering excitation waveform adds further control to the task of heat transfer in electronics cooling, where often frequency was the only previous control variable.
\end{abstract}

\section{Keywords}

Taxonomy

Corresponding Author

Order of Authors

Suggested reviewers
Pulsation; Mesochannel; Micro-PIV; Asymmetric waveform; Electronics cooling

Fluid Mechanics, Heat Transfer

Jaakko McEvoy

Jaakko McEvoy, Sajad Alimohammadi, Tim Persoons

Balkrishna Mehta, Anthony Robinson

\section{Submission Files Included in this PDF}

\section{File Name [File Type]}

ETFS_ICEFM2018_CoverLetter_J.McEvoy.pdf [Cover Letter]

ETFS response letter 15-07-2019.pdf [Response to Reviewers]

ETFS_ICEFM2018_Highlights_JMcEvoy.docx [Highlights]

Revised Manuscript ETFS Jaakko McEvoy 15072019 Highlighted.pdf [Manuscript File]

Conflict of Interest.pdf [Conflict of Interest]

\section{Submission Files Not Included in this PDF}

\author{
File Name [File Type] \\ SourceFiles.zip [LaTeX Source File]
}

To view all the submission files, including those not included in the PDF, click on the manuscript title on your EVISE Homepage, then click 'Download zip file'. 
Jaakko McEvoy

Parsons Building, Trinity College Dublin, Ireland | jmcevoy@tcd.ie

$14 / 12 / 2018$

Dr. Serhiy Yarusevych

Editor in Chief

Experimental Thermal and Fluid Sciences

\section{Dear Dr. Serhiy Yarusevych:}

I am pleased to submit an original research article entitled "Experimental investigation of pulsation waveforms in rectangular mesochannels for high heat flux electronics cooling" by Jaakko McEvoy, Sajad Alimohammadi and Tim Persoons for consideration for publication in the special ICEFM 2018 edition in Experimental Thermal and Fluid Sciences.

In this paper we demonstrate the enhancement of fluid pulsation amplitudes in mesochannels by altering the excitation waveform. We obtain increased wall shear while incurring negligible pressure drops using asymmetric waveforms.

The manuscript introduces a novel and simple solution for enhanced heat transfer in mesoscale channels and can easily be applied to micro/nanoscale devices.

The manuscript has not been published and is not under consideration for publication elsewhere. We have no conflict to disclose.

Thank you for your consideration.

\section{Sincerely,}

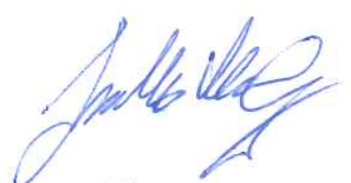

Jaakko McEvoy 
Dear Editor and Reviewer,

Thank you for organising the rereview of our manuscript and for providing detailed feedback. We have taken the Reviewers' comments into consideration and have revised our manuscript accordingly. Please find below a point by point response to the remarks made by the Reviewer. The original remarks are included in grey italic.

A highlighted version of the revised manuscript is included showing changes made to the manuscript. Wherever changes are made in response to a specific comment by a Reviewer, those are also highlighted in this response letter.

\section{Reviewer 1:}

Fig. 3: Please indicate the thermocouples for the inlet and outlet for the LMTD in the figure The model of thermocouples (TMTSS-020-G-6) used for the experiments have now been included in the manuscript. (Line 206)

L717: Please indicate the depth of correlation for the current experimental conditions

The combination of objective lens $(10 x / .30)$ with the seeding $(1.1 \mu)$ gives a correlation depth of approx. 26 $4 \mathrm{~m}$. (Line 171-172)

L770: Please use (F(-1)) consistently with or without outer brackets.

This issue has been rectified throughout the manuscript.

Fig. 14: Please use a log-log plot with same scales on the y-axis for a better comparability.

Figure 14, has been replotted with log-log scales. (Page 20)

Fig. 17: Figure has the wrong caption, please indicate Wo numbers in the x-label instead of frequencies. Furthermore the LMTD method is not explained in the text. At least give the abbreviation for readers that are not too familiar with heat exchanger characterization. I would also propose to use Kelvin instead of ${ }^{\circ} \mathrm{C}$ for the LMTD.

Apologies for the incorrect caption, this has been updated. Womersley numbers are now used to distinguish the data points instead of frequencies. LMTD has been briefly described in the text, (Line 333-337) .

Kelvin has been used instead of ${ }^{\circ} \mathrm{C}$ for the LMTD in the figure.

L1363: Here it is stated that the sinusoidal wave form shown only a negligible effects. However, for Wo $=5$ the heat transfer is close to the asymmetric wave forms (as also stated later in that section). Please clarify.

Due to physical limitations of the actuation speed of the pulsator at higher frequencies $(>25 \mathrm{~Hz})$ the impulse like stroke in the two asymmetric waveforms begins to slant.

The pulsator LVDT displacement sensor data shows some distortion of the impulse stroke in these high frequency cases. The authors expected this and therefore limited the study to a $\max$ of $25 \mathrm{~Hz}$.

At $5 \mathrm{~Hz}$ excitation the impulse stroke comprises of $10 \%(20 \mathrm{~ms})$ of the entire oscillation duration $(200 \mathrm{~ms})$, while at $25 \mathrm{~Hz}$ the impulse stroke comprises of $22.5 \%(9 \mathrm{~ms})$ of the 
oscillation duration (40ms). This is the cause of the asymmetric excitation waveforms having heat transfer enhancements close to the sinusoidal one at Wo $=5(25 \mathrm{~Hz})$.

To study this at higher frequencies requires the ability to generate high accuracy pulsation with complex waveforms at very high frequencies, which was impossible in this study.

The authors are currently working on obtaining IR thermography images of these pulsation waveforms at the same Womersley numbers (in a larger channel fitted with an Inconel sheet and a sapphire viewing window) to further understand what is the cause for the changing heat transfer enhancement.

The manuscript should again be checked for typos. For example (L497 'method' instead of 'methods', L570 'shown' instead of 'sown', L945 point missing before 'Due to ...', L1031 'overpowers' instead of 'over powers')

The manuscript has been thoroughly checked for typos. 
- Altering fluid pulsation waveform can significantly enhance fluid fluctuations in mesochannels

- Asymmetric excitation waveforms with sharp impulses results in higher order velocity fluctuations

- Wall shear and therefore heat transfer may be enhanced this way with negligible pressure drop penalty 


\section{Experimental investigation of flow pulsation waveforms \\ 2 \\ 3 \\ electronics cooling}

5

6

Department of Mechanical $\&$ Manufacturing Engineering, Trinity College, Dublin, Ireland

西

\section{Abstract}

8 The ever rising heat fluxes encountered in electronic devices present a chal9 lenging thermal engineering problem. Not only is heat transfer enhancement 10 a goal but more recently control of the enhancement is desired, especially in large scale data facilities where the heated outlet coolant fluid may be of use.

\section{2}

(1)

(1)

d

previous research being limited to only sinusoidally oscillating flows. In this

work the effect of symmetric and asymmetric excitation waveforms on heat

transfer with single phase pulsatile fluid flow in mesochannels is investigated through micro particle image velocimetry ( $\mu$-PIV) and a thermal test rig. The channel measures $25 \mathrm{~mm}, 0.58 \mathrm{~mm}$ and $1.15 \mathrm{~mm}$ in length, width and height respectively, giving a hydraulic diameter $\left(D_{h}\right)=771 \mu \mathrm{m}$. A $\mu$-PIV

\footnotetext{
*Corresponding author, jmcevoy@tcd.ie

Preprint submitted to Experimental Themal and Fluid Science, Trinity College, 15, 20019 Ireland
} 
stage with a Nikon 10x/0.3 objective coupled to a double pulsed Nd:YLF high-speed laser and CMOS camera $(1024 \times 1024$ pixels, 12 bit) were used for recording PIV images. The ability to operate both the camera and light 


\section{Introduction}

Traditionally low heat flux devices could be cooled by forced air convection, but with the rapid advances in microprocessor technology there exists a growing need to effectively cool heat fluxes as high as $300 \mathrm{~W} / \mathrm{cm}^{2}$, with the number predicted to rise to over $1000 \mathrm{~W} / \mathrm{cm}^{2}$ in the near future. The first example of the feasibility of using microchannels to combat high heat fluxes was demonstrated in the pioneering work of Tuckerman and Pease [1]. They demonstrated the ability to remove heat fluxes of $790 \mathrm{~W} / \mathrm{cm}^{2}$ in integrated silicon circuits. Their work inspired others to consider microchannel technologies for high heat flux removal from small scale applications to large industrial and aerospace applications.

The rapid growth in the data centre sector over the last decades has seen air cooling solutions reach their cooling limit in High Performance Computing (HPC) applications, and as a result the power densities in these facilities has plateaued. Due to the higher heat capacity of water there as been a steady push towards liquid cooled systems in HPC as well as standard data centre facilities who do not want to hit a thermal bottleneck in the future [2].

The advantage of liquid cooled systems is the ability to extract high grade waste heat for secondary processes (e.g. district heating and low temperature Organic Rankine Cycles) when some heat transfer enhancement techniques, such as flow pulsation, electrostatic fields and vibration are utilised [3] [4]. Persoons et al. achieved experimentally an enhancement factor of up to $40 \%$ in the heat transfer rate over steady flow with the use of pulsation $(6<$ 
$\left.W_{o}<17,0.002<R e_{p} / R e<3\right)[5]$. They defined the pulsating Reynolds number as, $R e_{p}=U_{p} D_{h} / \nu$, where $U_{p}$ is the mean channel pulsating velocity amplitude. In an analytical study, Brereton and Jiang also reported an enhancement of $40 \%$ under similar conditions, $\left(15<W_{o}<30, R e_{p} / R e=\right.$ 2.5) [6]. A extensive body of work exists in literature for analytical solutions to laminar pulsating flows in rectangular channels, which can be used to gain a deeper understanding of the coupling mechanism between thermal and fluid characteristics $[7,8,9,10]$.

The mechanism of interest for heat transfer in pulsatile flows has been investigated since 1851 with Stokes second problem, where a one dimensional flat plate oscillating in the streamwise direction was considered [11]. The problem solves for the transverse velocity oscillations from the plate, which decay with increased distance from the plate. The oscillation from the plate propagates as a dampened wave normal to the direction of oscillation, with the oscillating amplitude reducing to approximately zero at a distance known as the Stokes boundary layer thickness $\delta$, see Equation 1.

$$
\delta=2 \pi \sqrt{\frac{2 \nu}{\omega}}
$$

Where $\nu$ is the kinematic viscosity and $\omega$ is the angular velocity.

The oscillating conditions within a channel can be characterised by the nondimensional Womersley number, which describes the ratio of transient to 
viscous forces introduced by Womersley [12].

$$
W_{O}=\frac{d_{h}}{2} \sqrt{\frac{\omega}{\nu}}
$$

Flow pulsation and oscillation in single phase fluids with an aim for improved heat transfer from macro scale to the nano scale has been studied before using a range of different methodologies for velocity measurements. Many of the early studies used the intrusive velocity measurement method of hotwire anemometry to investigate the effects of oscillation, while others used laser Doppler velocimetry to obtain non-intrusive point measurements of the flow properties. There remains a lack of strong cohesion in the literature between these experimental studies for similar Womersley numbers, largely due to the difficulty of the examination. Denison and Stevenson used a directionally sensitive laser velocimetry methodology to measure unsteady oscillating flows for $1.71 \leq \mathrm{Wo} \leq 14.1$ [13]. Clamen and Minton studied the effect of an oscillating pipe on the contained flow for a Reynolds number range of 1275 - 2900, and found good agreement with laminar theory at the low end of the range, but some deviation at higher Re [14]. Ojha et al. demonstrated the effectiveness of a photochromatic dye excited by a laser to capture a snapshot of the fluid flow profile, with good agreement to Womersley's model flow [15]. Blythman et al. used experimental PIV data to verify their analytical model for a two dimensional rectangular channel, with good agreement [7]. Ray et al. were one of the few who have studied 
non-sinusoidal driven excitation waveforms. They used a hot-wire probe and multiple pressure sensors to validate their analytical model for a wide range of Womersley numbers, $0.15<W_{o}<21$ and for a sinusoidal and triangular waveform. Roslan et al. conducted a purely analytical study on the effect of waveform on heat transfer for laminar duct flows [16]. They concluded that the excitation waveform does play a notable role in heat transfer performance.

Table 1: Previous studies of pulsation and/or oscillation in single phase laminar flows

\begin{tabular}{|c|c|c|c|c|c|}
\hline Study & Cross section & Measurement Method & Wo & Waveform & Type* \\
\hline$[13]$ & Circular & LDV & $\begin{array}{ll}1.71 & - \\
14.1\end{array}$ & Sine & $\mathrm{E}$ \\
\hline$[15]$ & Circular & Photochromic dye & 7.52 & Sine & $\mathrm{A} \& \mathrm{E}$ \\
\hline$[17]$ & Circular & Hot wire & $0.15-21$ & Sine \& Triangle & $A \& E$ \\
\hline$[14]$ & Circular & $\begin{array}{l}\text { LDV \& Hydrogen bub- } \\
\text { ble }\end{array}$ & $\begin{array}{l}11.2 \quad- \\
26.7\end{array}$ & Sine & $\mathrm{E}$ \\
\hline$[10]$ & Rectangular & PIV & 3.34 & Sine & $\mathrm{E}$ \\
\hline$[16]$ & Circular & NA & - & Square \& Sawtooth & A \\
\hline Present study & Rectangular & $\mu$-PIV & $1-5$ & $\begin{array}{l}\text { Sine \& Triangle \& } \\
\text { Asymmetric Sine }\end{array}$ & $\mathrm{E}$ \\
\hline
\end{tabular}

Mehta and Khandekar [18] studied pulsation in square channel using infrared thermography to analyze the effect of heat transfer for Womersley numbers of $0.8,3.4,5.9$. They concluded that for $W o<0.8$ pulsation has a negative effect on heat transfer, as the diffusion time scale is similar to the time scale of excitation. For higher frequencies $\left(W_{o}=3.4 \& 5.9\right)$, the convection term dominates, resulting in small enhancement, but not of any use in real life cooling applications. On the other hand, research indicating a $40 \%$ enhancement in heat transfer as discussed above should be investigated further $[5,6]$. Preliminary data presented by McEvoy et al. on the effect of pulsation waveform on the fluctuating velocity profiles and wall shear in mesochannels, displayed a large amplification effect when impulse like asymmetric excita- 
138

tion waveforms are utilised [19]. This paper presents the enhancement in magnitude of the fluctuating velocity component in asymmetric waveforms and demonstrates their impact on heat transfer through a thermal analysis. The paper also analyses pressure drops and cavity harmonic frequencies to wholly characterise the system.

\section{Experimental approach}

\section{1. $\mu-P I V$ facility}

The $\mu$-PIV test section consists of an array of 21 rectangular channels with widths of $0.58 \mathrm{~mm}$ and heights of $1.15 \mathrm{~mm}$. Each channel is $25 \mathrm{~mm}$ long and micro-milled into a copper block. The copper block sits within a PEEK housing and is covered with a $1.15 \mathrm{~mm}$ thick glass slide to allow full optical access to all channels. The entire assembly is tightly clamped with an aluminium cover cap, with 16 individual tightening screws along the perimeter.

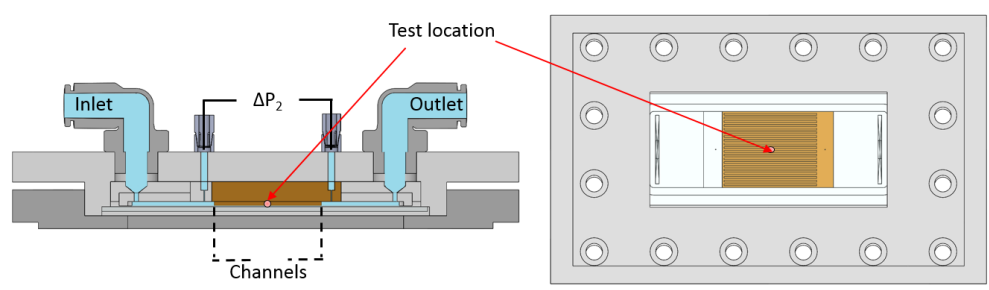

Figure 1: Test section side and plan view

A Bronkhorst M15 mass flow meter is used for high accuracy flow measurements. Two differential pressure transducers are used to measure the 
pressure drop, one across the entire test section (Omega 0-35 $\mathrm{kPa}$ custom pressure transducer) and the other across the central channel (Honeywell 26PC pressure transducer 0-1 psi), through $0.2 \mathrm{~mm}$ pressure tap holes. The fluid is driven by a Fluidotech FG200 series magnetic drive gear pump, which offers smooth pulseless flow. For accurate monitoring of microscope stage location two Omron ZX-L-N laser displacement sensors are used in the X and Y directions. Flow pulsation is achieved through a Noliac piezo ring bender (CMBR08) driven by two high voltage power supplies and housed in a custom-built chamber located directly before the test section. One power supply (EA-PS 8360-10T) is used to supply a 0-200V constant voltage across the piezo element, with the second power supply (Trek model 2205) being used to amplify the control voltage from $0-4 \mathrm{~V}$ to $0-200 \mathrm{~V}$. The waveforms seen in Fig. 2 are generated by a TTi TG315 function generator and monitored on an IDS-1054B oscilloscope and through LabView. The implicit recursive function shown in Eq. (3) describe the leading and lagging waveforms. Where $a$ determines the amplitude, $f$ the frequency, $t$ the time step. Asymmetric skewness is controlled by the $k$ term, where $k=-1$ gives a left skewed function (leading), and $k=1$ gives a right skewed sine function (lagging), ( $k=0$ results in no skew, i.e. symmetric waveform). The leading function waveform, shown in Fig. 2(c) will be referred to as $F_{(-1)}$, and the lagging function in Fig. $2(\mathrm{~d})$ as $F_{(1)}$, with both $F_{(-1)}$ and $F_{(1)}=y^{(N)}$, with $y^{(N)}$ defined in Eq. (3). 


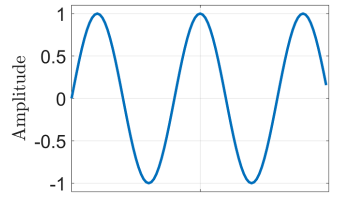

(a) Sine

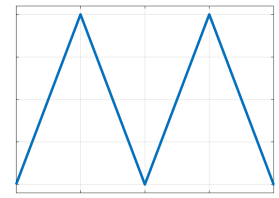

(b) Triangle

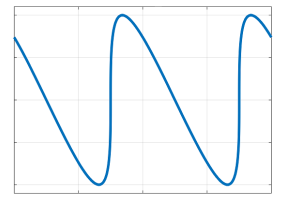

(c) Leading, $F_{(-1)}$

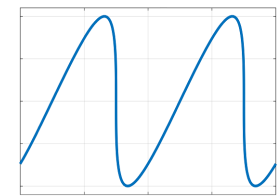

(d) Lagging, $F_{(1)}$

Figure 2: Excitation waveforms. 
as the one used in this work. A similar image pre-processing method to the one outlined by Lindken et al. for their self-calibration procedure is used to reduce the adverse effect of stuck seeding along the channel walls [20].

- Subtraction of a sliding minimum over 5 images $\rightarrow$ reducing constant background noise.

- $3 \times 3$ Gaussian smoothing filter $\rightarrow$ reducing random noise and enhancing signal to noise ratio.

- Subtract $9 \times 9$ sliding minimum of individual images $\rightarrow$ further reduction of noise.

- Sliding maximum over time $\rightarrow$ overlaps multiple low image density PIV images to obtain high seeding image density.

The sliding maximum was used to increase the seeding image density to acceptable levels ( $\sim 10$ particles in the last interrogation window) as outlined by Raffel et al. [21]. To achieve this the camera frame rate was set to a multiple $(N)$ of the pulsation frequency, where $N$ becomes the number of data points per cycle, and images can be overlapped at exactly the same phase. A sliding maximum filter was used instead of correlation averaging as no discernible difference was found between the two computed vector fields. 


\subsection{Thermal test rig}

For thermal analysis a copper block with a single channel is used instead of the full 21 channels. A copper heat spreader with a $20 \mathrm{~W}$ cartridge heater (Omega CSS-10120/120V) at its core is mounted through the back of the test section as shown below in Fig. 3. Thermal grease $(k=11.8 \mathrm{~W} / \mathrm{mK})$ is applied between the copper channel and heat spreader. Five T-type thermocouples (Omega TMTSS-020-G-6) are located in blind holes drilled to within $0.5 \mathrm{~mm}$ of the channel wall. The first thermocouple is located $0.5 \mathrm{~mm}$ from the entrance, with each following one being spaced apart by $6 \mathrm{~mm}$. Inlet and outlet fluid temperatures are measured using two additional (Omega TMTSS-020-G-6) thermocouple probes located directly before and after the test section. The water reservoir is air cooled to maintain inlet fluid temperatures constant throughout all tests.
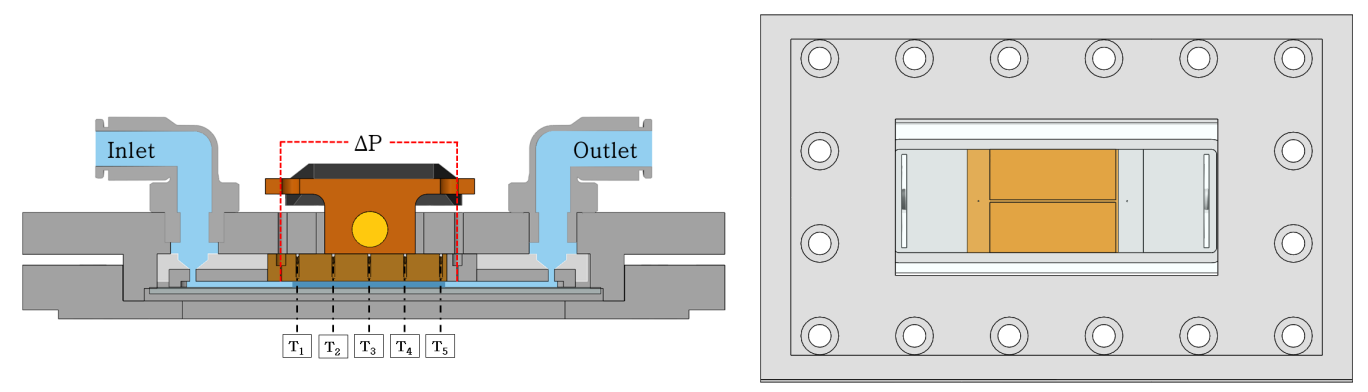

Figure 3: Test section side and plan view 


\section{Results and Discussion}

The effect of oscillation using sinusoidal and non-sinusoidal waveforms on velocity and pressure drops are reported for a mean Reynolds number of 150, and Womersley numbers of 1.0, 2.2, 4.1 and $5.0(f=1.00 \mathrm{~Hz}, 5.00 \mathrm{~Hz}$, $16.55 \mathrm{~Hz}$ and $25.00 \mathrm{~Hz})$. A steady $(\mathrm{OHz})$ case was also tested and compared to the analytical solution for validation of the method. For a mean Reynolds number of 150 and hydraulic diameter of $771 \mu m$ the hydrodynamic developing length is $5.8 \mathrm{~mm}$. When pulsation is utilised the pulsatile Reynolds number can be as high as 250, and therefore the hydrodynamic entrance length increases to $9.6 \mathrm{~mm}$. To ensure all $\mu$-PIV measurements were taken in a region of fully developed flow the imaging location is chosen to be in the central channel far downstream of the entrance $(x=12.5 \mathrm{~mm})$. The flow velocity experienced is very high due to the small cross-sectional area. This results in the effect of the near wall oscillation being enveloped in the flow. The piezo actuator was used to control the flow oscillation with minimal oscillation amplitudes $Q_{t} / Q_{0}$, in the region of 0.0542 , where $Q_{t}$ is the oscillating flow rate amplitude and $Q_{0}$ is the steady flow rate. The effect of these parameters can be most clearly be seen at low frequencies $(1 \mathrm{~Hz})$, where the oscillating velocity is approximately $5 \%$ of the mean velocity for a sinusoidal and triangular waveform. Analysis of the LVDT displacement sensor showed that the triangular wave was only slightly distorted at the highest frequency $(25 \mathrm{~Hz})$, but still reached $96 \%$ of the full stroke amplitude 
240

241 242 243 at higher frequencies. The waveform amplitude was not affected at any other frequency. The primary low order behaviour of the triangular wave is therefore very similar to the sine wave, and the behaviour of the system was not found to be very sensitive to the higher order harmonics of the triangle wave, as discussed below. It was noted that at higher frequencies the asymmetric functions exhibited a lag in time along their vertical impulse stroke.

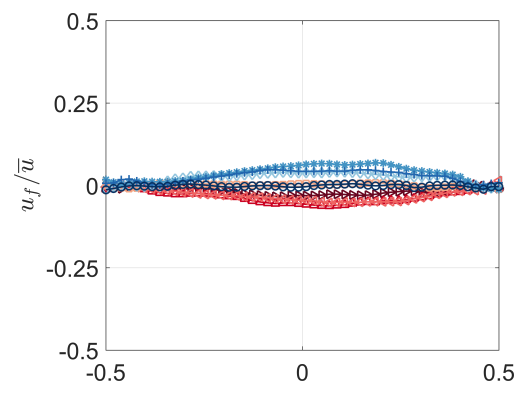

(a) Sine

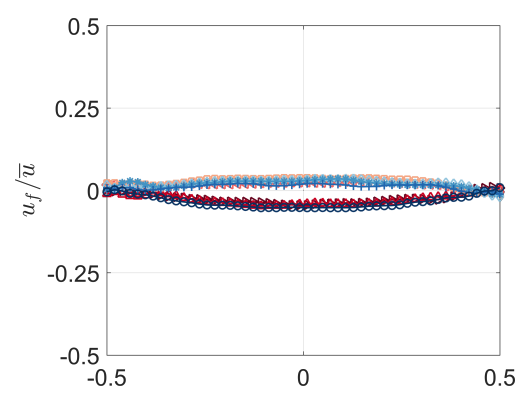

(c) $F_{(-1)}$

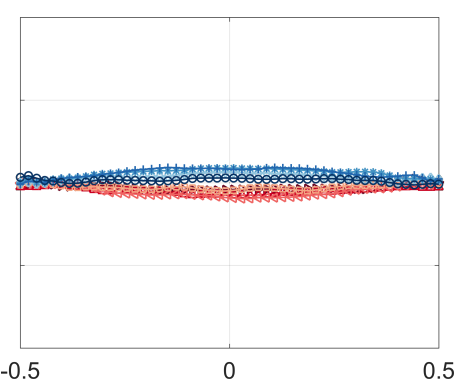

(b) Triangle

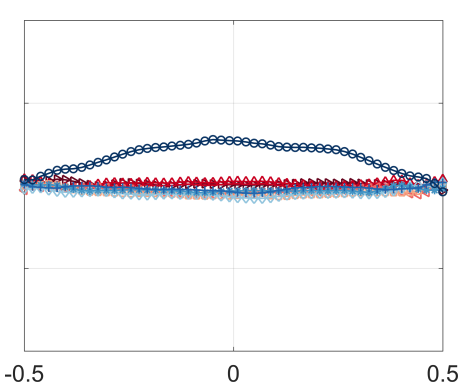

(d) $F_{(1)}$

Figure 4: Phase-averaged fluctuating velocity profiles at $f=1.00 \mathrm{~Hz}(\mathrm{Wo}=1.0)$.

The effect of the asymmetric waveforms $\left(F_{(-1)}\right.$ and $\left.F_{(1)}\right)$ on the fluctuating velocity is immediately clear from Fig. 4(d). Due to the relatively low velocity fluctuation at low frequencies in the flow, the phase-averaged fluctuating velocity profiles exhibit significant variation across the span of 


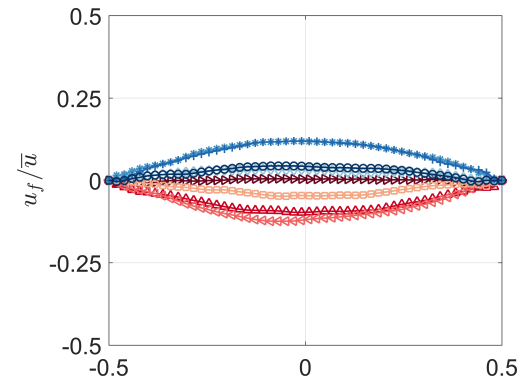

(a) Sine

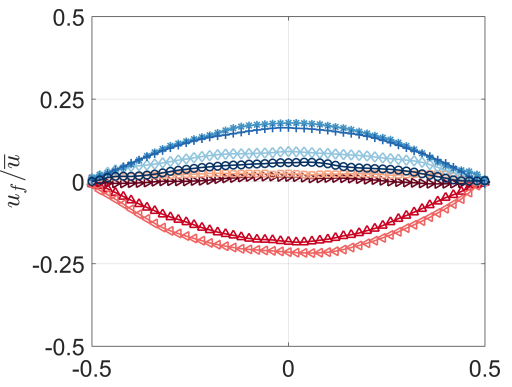

(c) $F_{(-1)}$

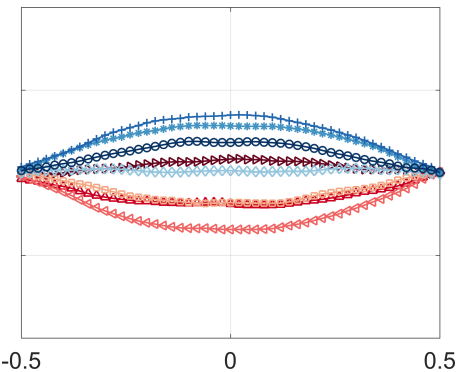

(b) Triangle

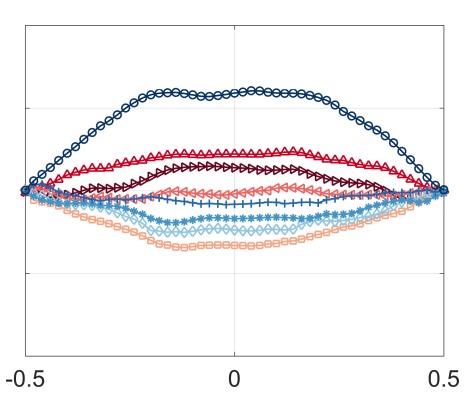

(d) $F_{(1)}$

Figure 5: Phase-averaged fluctuating velocity profiles at $f=5.00 \mathrm{~Hz}(\mathrm{Wo}=2.2)$.

the channel for both low frequency cases shown in Fig. 4 and 5. The fluctuating components of velocity are calculated by subtracting the mean profile of all instances. In all cases the measurement plane was at the centre of the channel height, $z=0.5 \mathrm{~mm}$. The sharp up/down-stroke in both asymmetric functions $\left(F_{(-1)}\right.$ and $\left.F_{(1)}\right)$ oscillations causes a rapid shift in the flow velocity, where inertial forces prevail for a brief period. At the wall the viscous stresses retard the fluid momentum and switch rapidly with varying pressure gradients, resulting in the over/undershoots visible in Fig. 6 (c) \& (d) and 7 (c) \& (d). As the excitation frequency is increased, the effect of the rapidly accelerating and decelerating flow can clearly be seen in either 


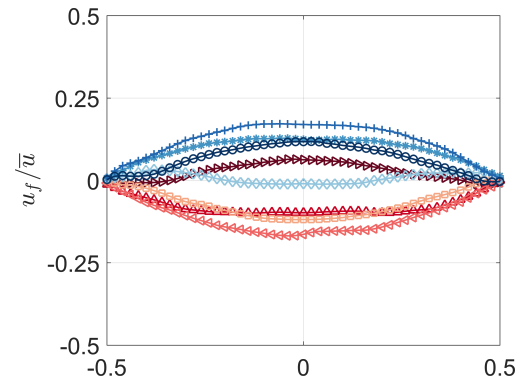

(a) Sine

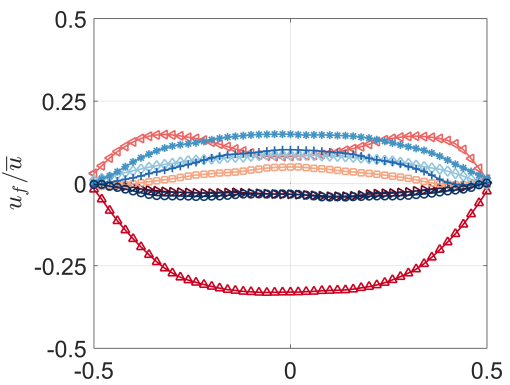

(c) $F_{(-1)}$

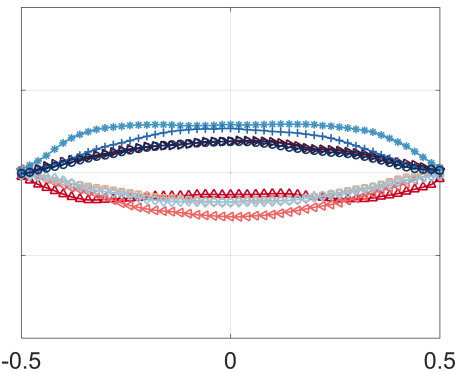

(b) Triangle

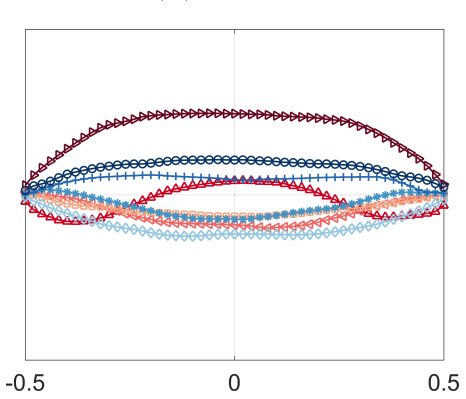

(d) $F_{(1)}$

Figure 6: Phase-averaged fluctuating velocity profiles at $f=16.55 \mathrm{~Hz}(W o=4.1)$.

the triangular waveform and both asymmetric function waveforms, due to their sharp inflection points. The leading function $F_{(-1)}$ described by Eq. (3), exhibits lower fluctuating amplitudes compared to the right skewed $F_{(1)}$ function. This is due to the direction of the steep impulse stroke imposed upon the flow. For $F_{(-1)}$, the imposed rapid acceleration is in the direction of flow resulting in very low velocity fluctuation over one cycle, but increasing the overall pressure drop in the channel averaged over one cycle due to 


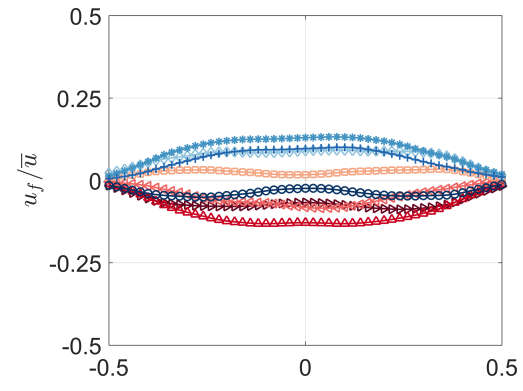

(a) Sine

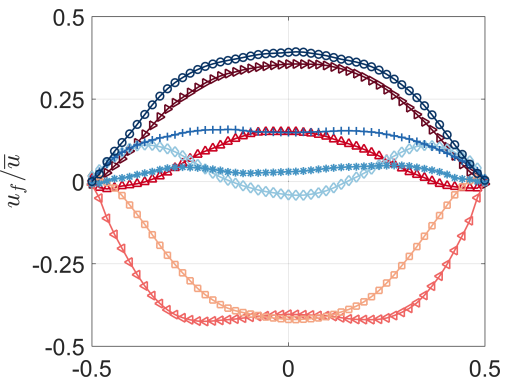

(c) $F_{(-1)}$

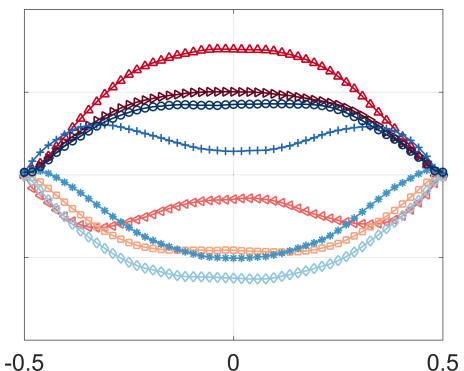

(b) Triangle

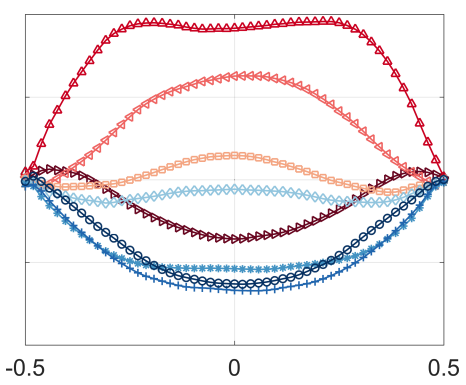

(d) $F_{(1)}$

Figure 7: Phase-averaged fluctuating velocity profiles at $f=25.00 \mathrm{~Hz}(\mathrm{Wo}=5.0)$.

opposite to the overall flow, resulting in momentary high fluctuations and reduced overall pressure drop. The pressure gradient, $d p / d x$ calculated from the $\mu$-PIV velocity fields rise with increased fluctuations as expected. At $f=$ $5 \mathrm{~Hz}$ the now rapidly switching pressure gradients within the viscous dominated near-wall region leads to the flow profiles displaying the annular effect. Further increasing the frequency to $16.55 \mathrm{~Hz}$ and $25 \mathrm{~Hz}$, the flow begins to loose its quasi-steady characteristics. At $25 \mathrm{~Hz}$ both asymmetric functions demonstrate approximately similar amplitudes of velocity fluctuation indicating that the waveform acts more as a pure impulse function, and would have little to no variation at higher frequencies. 

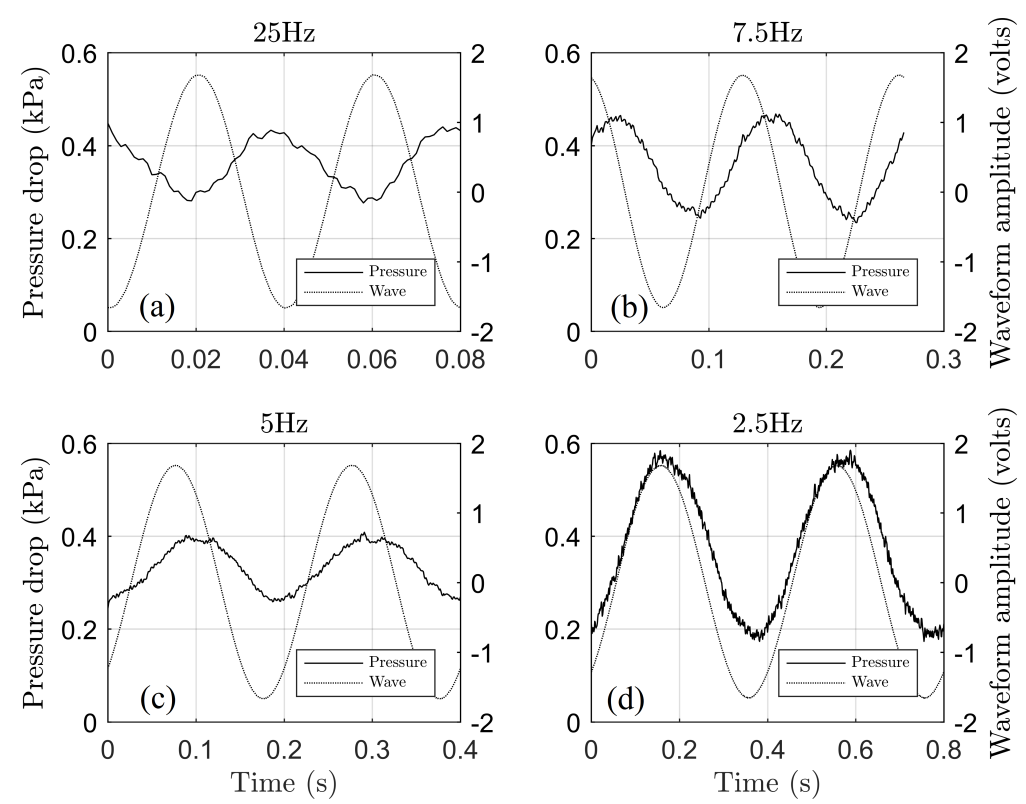

Figure 8: Symmetric sinusoidal waveform; (a) $25 \mathrm{~Hz}$ $(\mathrm{Wo}=5),(\mathrm{b}) 7.5 \mathrm{~Hz}(\mathrm{Wo}=2.75),(\mathrm{c}) 5 \mathrm{~Hz}(\mathrm{Wo}=2.2)$, (d) $2.5 \mathrm{~Hz}(\mathrm{Wo}=1.6)$. Pressure plot is instantaneous data from $26 \mathrm{PC}$ pressure transducer

Figure 9 shows the pressure readings from the more sensitive 26PC pressure transducer and exhibit a higher order oscillation for non-sinusoidal waveforms, with a frequency around $50 \mathrm{~Hz}$. These higher order fluctuations are not present in the sinusoidal excitation shown in Figs. 8. This was found to be the Helmholtz resonant frequency which was excited by the sharp impulselike waveforms.

Following a similar analysis conducted by Persoons et al., where the stiffness of the tubing and channel test section along with the associated fluid are considered, the combined system Helmholtz resonance frequency can be calculated [5]. Calculating the resonance frequency as $f_{0}=1 /(2 \pi) \sqrt{k / m}$, 

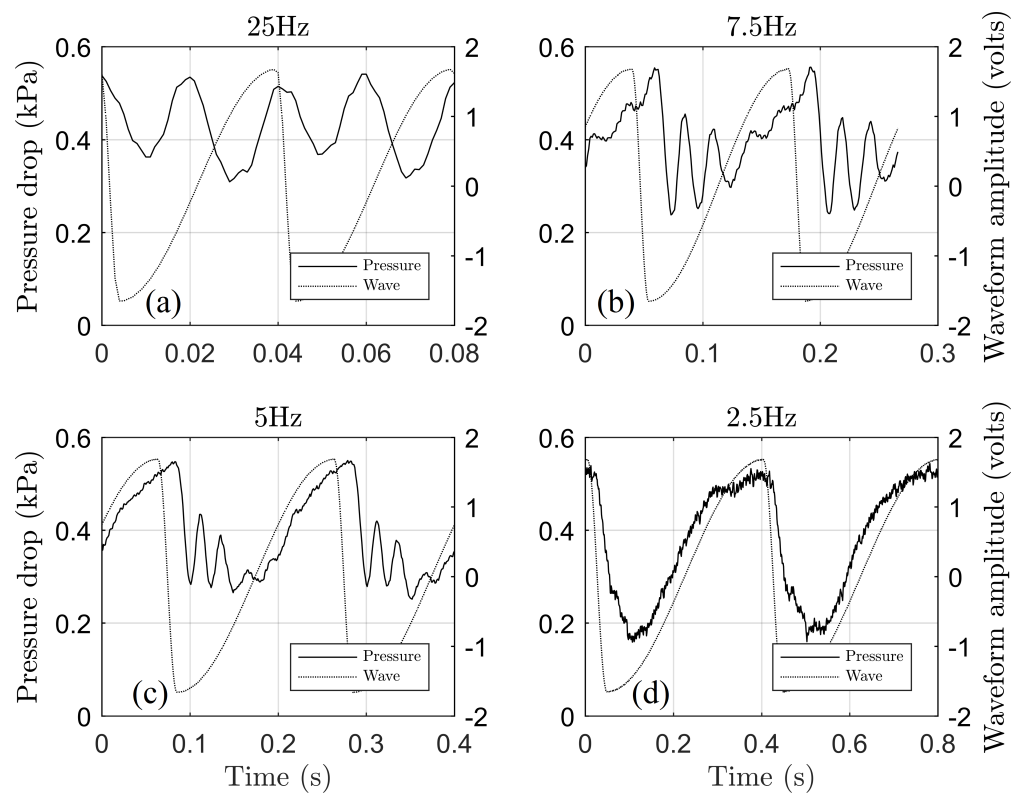

Figure 9: Asymmetric waveform displaying Helmholtz resonance at high frequency; (a) $25 \mathrm{~Hz}(\mathrm{Wo}=5)$, (b) $7.5 \mathrm{~Hz}(\mathrm{Wo}=2.75),(\mathrm{c}) 5 \mathrm{~Hz}(\mathrm{Wo}=2.2)$, (d) $2.5 \mathrm{~Hz}$ (Wo $=1.6$ ). Pressure plot is instantaneous data from $26 \mathrm{PC}$ pressure transducer

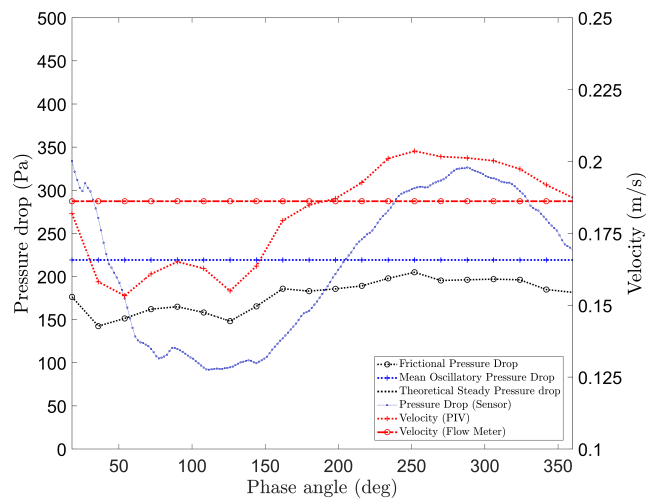

Figure 10: $F_{(-1)} 5 \mathrm{~Hz}(\mathrm{Wo}=2.2)$ velocity and pressure over 1 cycle

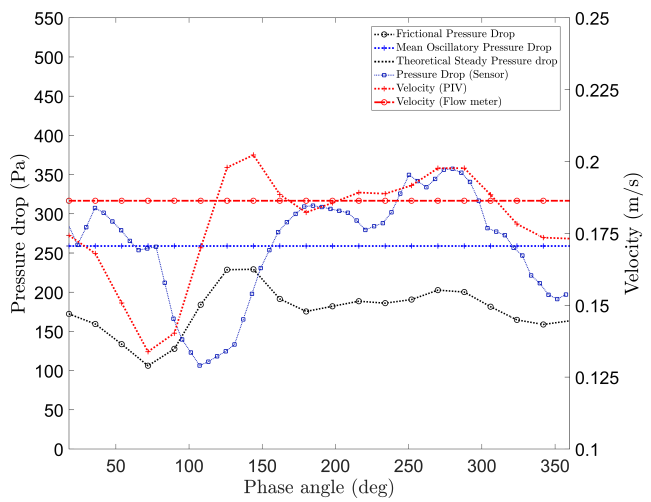

Figure 11: $F_{(-1)} 16.55 \mathrm{~Hz}(\mathrm{Wo}=4.1)$ velocity and pressure over 1 cycle 


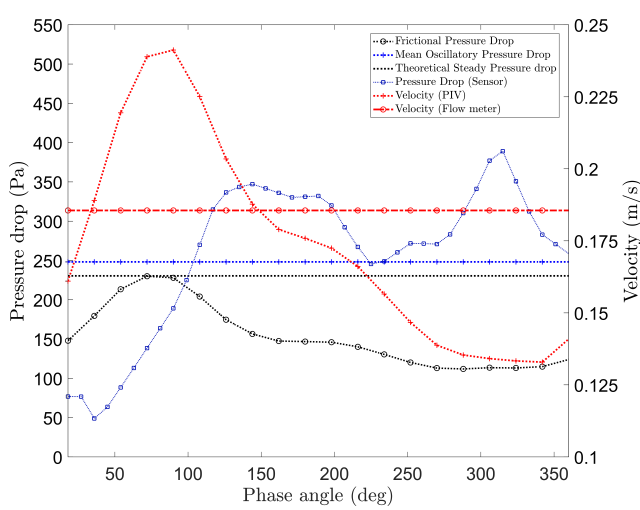

Figure 12: $F_{(1)} 25 \mathrm{~Hz}$ velocity and pressure over 1 cycle

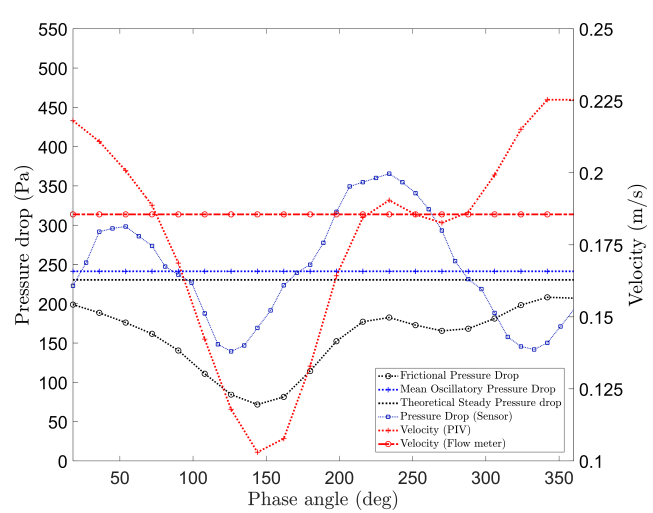

Figure 13: $F_{(-1)} 25 \mathrm{~Hz}$ velocity and pressure over 1 cycle

284 where $k$ is the system stiffness and $m$ is the mass of the oscillating fluid. 285 The system compliance $1 / k$ is the sum of the fluidic and structural com286 pliance, $1 / k=1 / k_{s}+1 / k_{f}$. The fluidic compliance can be obtained from, ${ }_{287} 1 / k_{f}=V /\left(\rho c^{2} A^{2}\right)$, where $V$ is the volume of fluid in the tubing and test ${ }_{288}$ section under consideration, $A$ is the cross sectional area of the tube and $c$ is 289 the speed of sound in water at $1 \mathrm{~atm}$ and $25^{\circ} \mathrm{C}$ and is approximately equal to $2901500 \mathrm{~m} / \mathrm{s}$. As the copper test section is small and has a very low compliance 291 the structural compliance component is mainly made up of the cylindrical 292 tubing, and is given by $1 / k_{s}=L_{t} /(\pi E t \sqrt{A / \pi})$, where $L_{t}$ is the tube length, ${ }_{293} E$ is the tensile modulus of the tubing and $t$ is the tube wall thickness. For 294 this case the combined system Helmholtz resonance frequency was calculated 295 to be between 45 and $55 \mathrm{~Hz}$ for the system.

296 Velocity and pressure data over one oscillation for both $F_{(1)}$ and $F_{(-1)}$ 297 can be seen in Fig. 10 - 13. At the higher frequency the fluctuation in pressure readings is evident, as well as the instantaneous velocity, possibly 


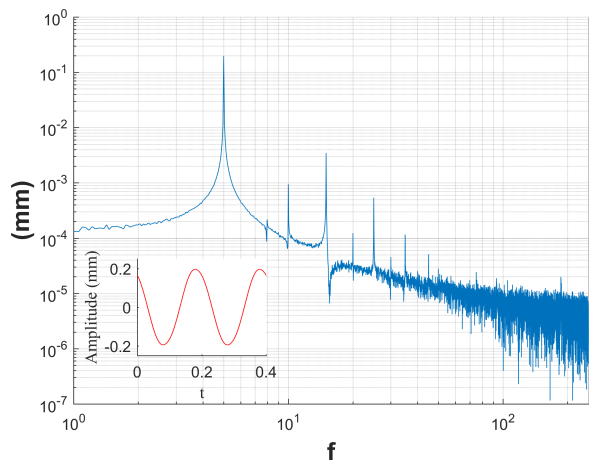

(a)

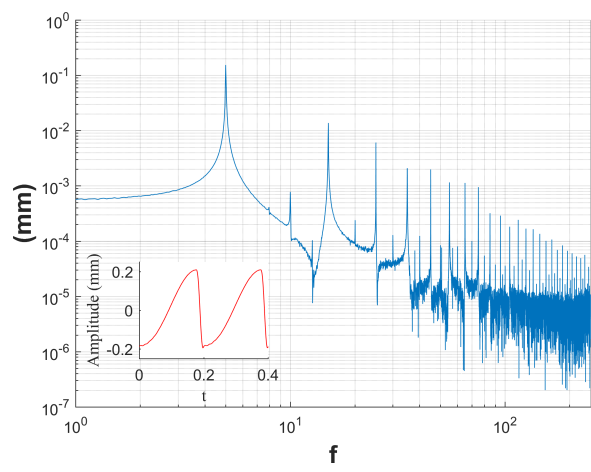

(c)

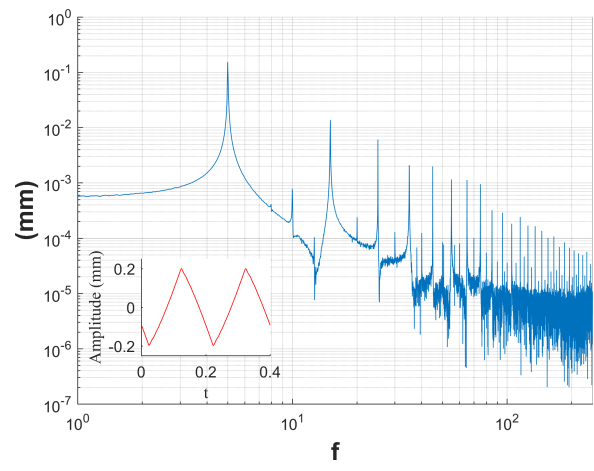

(b)

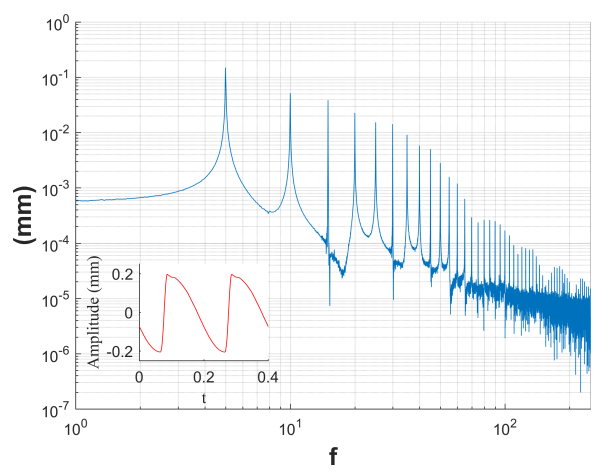

(d)

Figure 14: Higher order fluctuations in waveform signal, $f=5.00 \mathrm{~Hz}(W o=2.24)$ : (a) Sine (b) Triangle (c) $F_{(-1)}$ and, (d) $F_{(1)}$. 
an indicator of early transition to turbulence or chaotic advection. With $F_{(1)}$ the impulse stroke in the direction of the flow results in a sharp velocity spike which gradually falls. The pressure data follows this trend until the cavity resonance causes a positive pressure spike at $250^{\circ}$. Due to the pressure spike occurring in the "relaxing" phase of the stroke, it overpowers and is dominant.

The displacement sensor located on the pulsator allowed us to verify the full stroke length was completed at high frequencies. Analysis of the displacement shape mirrors the input excitation waveform and allows for high-order fluctuations to be shown through a fast Fourier transform (FFT). Figure 14 displays the data obtained form FFT for each waveform. The two asymmetric waveforms exhibit decaying higher order frequencies which could indicate enhanced mixing and heat transfer. Analysis of the averaged pressure data over extended period of time shows reduced pressure drops for both triangular and $F_{(-1)}$ waveforms, see Fig. 15. Both of these waveforms displayed large velocity fluctuations in the opposite streamwise direction, which explains their reduced pressure drop.

The effect of sinusoidal oscillation on heat transfer has provided inconclusive results in the past, with many studies finding negligible or adverse effects. Most of these studies used a pure sinusoidal waveform, which has been shown here to have a low impact on the mean flow oscillating amplitude and therefore may explain its inefficient narrowing of the thermal boundary layer. The scaling of the velocity fluctuation with increasing frequency is also 

sink.

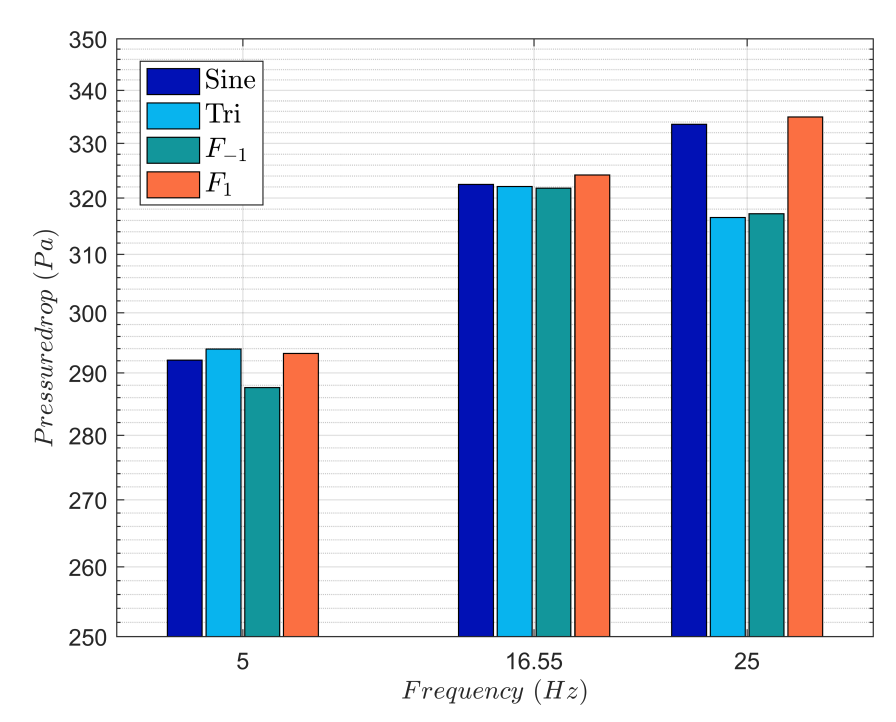

Figure 15: Pressure drop comparison for waveform and frequency fluctuation are found with the $F_{(1)}$ waveform, this is due to rapid deceleration and possible flow reversal at lower flow rates, which may have a negative effect on heat transfer as warmer fluid is pulled back towards the entrance of the channel, reducing the overall temperature difference across the heat

significantly lower for the pure sinusoidal tests. While higher amplitudes of

(1)

(10

flor

S 31

32 The recorded data over all frequencies and waveforms is displayed in Fig. 17.

333 The log mean temperature difference (LMTD) is commonly used in heat 
exchangers to calculate the temperature driving force for heat transfer in a

335 system. For this study the log mean temperature difference is estimated by 336 Eq. 4, where $T_{b}, T_{i n}$, and $T_{\text {out }}$ are the channel base temperature, inlet fluid 337 temperature and outlet fluid temperature respectively.

$$
\Delta T_{L M T D}=\frac{\left(T_{\text {out }}-T_{\text {in }}\right)}{\ln \left(\frac{T_{b}-T_{\text {in }}}{T_{b}-T_{\text {out }}}\right)}
$$

${ }_{338}$ For low excitation frequencies $(1 H z)$ there is no discernible difference 339 between the pulsation waveforms used. Above $5 \mathrm{~Hz}$ the difference in temper340 ature and therefore heat transfer enhancement becomes clearer, with the two 341 asymmetric excitation waveforms displaying lowest temperatures. In cases 342 where symmetric waveforms with lower frequencies $\left(W_{O}<4.1\right)$ are used the 


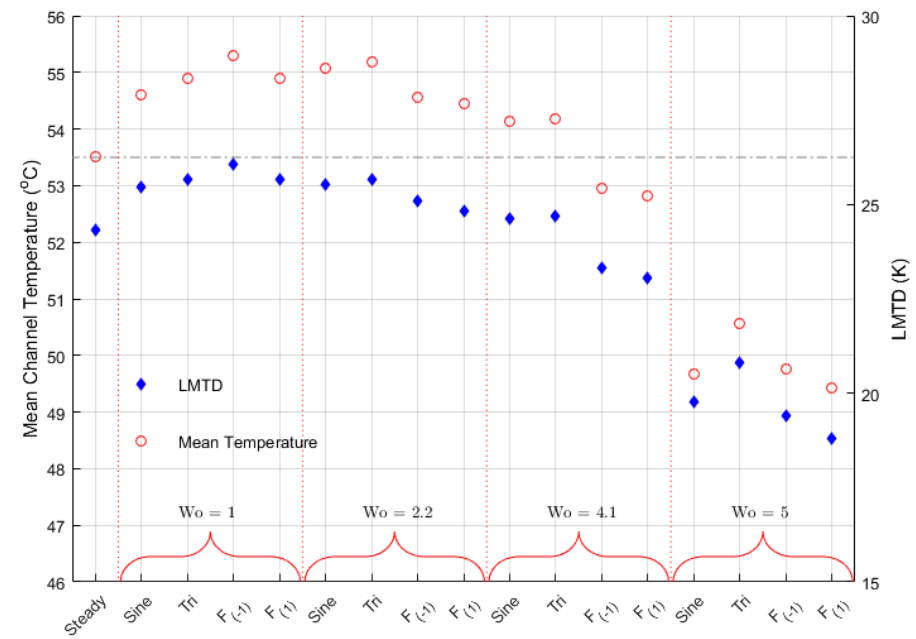

Figure 17: Mean channel temperature and log mean temperature difference (LMTD)

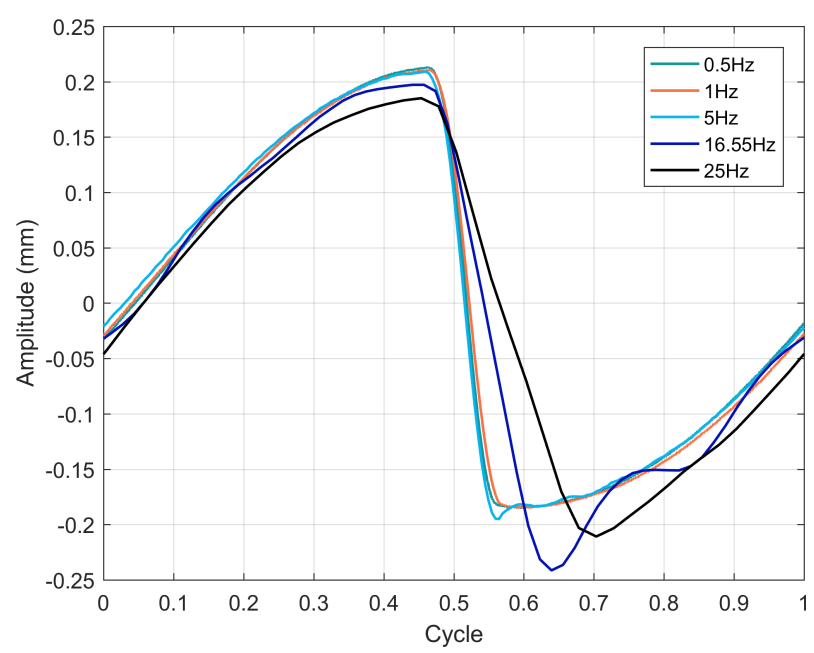

Figure 18: Deformation of asymmetric waveform with increasing frequency 
effect of pulsation has a negative effect on heat transfer, due to the diffusion time scale being close to the excitation time scale. This is in agreement with the findings of Mehta and Khandekar, but with a higher transition Womersley number to heat transfer enhancement [18]. As excitation frequency is increased past $W_{o}=4.1$ the surface temperature clearly drops for all waveforms with the best enhancement being found for the asymmetric waveform $F_{(1)}$. This enhancement in heat transfer can be contributed to the large streamwise velocity fluctuations observed through $\mu$-PIV. At the highest excitation frequency studied $\left(W_{O}=5\right)$ the enhancement in heat transfer of the two asymmetric waveforms over the sinusoidal excitation case is reduced slightly. This was found to be due to the slight deformation of the asymmetric excitation waveforms at higher frequencies, see Fig. 18. At lower frequencies $\left(W_{o}<4.1\right)$ the impulse stroke comprises of approximately $10 \%$ of the pulsation period, while at higher frequencies $\left(W_{O}=5\right)$ it can comprise 7 of up to $22.5 \%$ of the period. This is due the physical limitations of the pulsator system. The higher temperatures recorded for all triangular cases over $1 H z$ could be due to the sharp symmetric impulse like stroke, leading to high inertial forces in the channel in both directions. This could retard the development of near wall oscillations, leading to reduced wall shear and heat transfer. The varied effect of pulsation on heat transfer over such a small range of Womersley number somewhat explains the mixed opinion in the literature on its merit for heat transfer enhancement. In practice it is difficult to generate high frequency pulsations to achieve Womersley numbers above 
3667 in channels of this size. To achieve the large inertial forces associated with 367 high enhancement in heat transfer in microchannels would require systems 368 that could deliver excitation frequencies above $1 \mathrm{kHz}$. 


\section{Conclusion}

The effects of varying waveform and frequency on single phase fully developed flow within a mesochannel heat sink array has been demonstrated, though an experimental $\mu$-PIV and thermal analysis approach. The effect of pure sinusoidal oscillation was shown to have a low impact on possible heat transfer enhancement, as is suggested in the literature. For a Womersley number range of $W_{o}=1$ to 5 , the sinusoidal waveform effects showed negligible alteration. Similar results are observed for a triangular waveform, with the exception of high frequency where the system acts more like an impulse-driven oscillation giving large velocity fluctuations but poor heat transfer enhancement. The two asymmetric functions display some interesting preliminary results for transient velocity fluctuations, without a large pressure drop trade-off. They also consistently displayed the highest enhancement in heat transfer. Waveform $F_{(1)}$ at $25 \mathrm{~Hz}$ displayed the highest enhancement with a $28 \%$ increase in heat transfer over steady flow case, and a $4.5 \%$ enhancement over the standard sinusoidal excitation at the same frequency. Deformation of the excitation waveforms using sharp impulse like strokes $\left(F_{(1)}\right.$ and $\left.F_{(-1)}\right)$ at higher frequencies $\left(W_{o}>4.1\right)$ resulted in the reduction of heat transfer enhancement between the sinusoidal and asymmetric waveforms. Further research is required in the area of heat transfer and entrance/exit locations. Future studies should focus on discretizing the near wall region of the channel under higher magnification. The analytical investigation of the asymmetric 
waveforms should be investigated for comparison with experimental data.

\section{Acknowledgements}

This work has emanated from research conducted with the financial support of Science Foundation Ireland under the SFI Strategic Partnership Programme Grant Number SFI/15/SPP/E3125. The authors also would also like to acknowledge the support of the Irish Research Council (IRC) under grant number GOIPD/2016/216

\section{References}

[1] D. B. Tuckerman, R. F. W. Pease, High-performance heat sinking for VLSI, IEEE Electron Device Letters 2 (5) (1981) 126-129. doi:10.1109/EDL.1981.25367.

[2] S. V. Garimella, T. Persoons, J. A. Weibel, V. Gektin, Electronics Thermal Management in Information and Communications Technologies: Challenges and Future Directions, IEEE Transactions on Components, Packaging and Manufacturing Technology (in press). doi:10.1109/TCPMT.2016.2603600.

[3] M. E. Steinke, Single-phase liquid flow and heat transfer in plain and enhanced silicon microchannels, Ph.D. thesis, Rochester Institute of Technology (2005). 
${ }_{411}$ [4] M. Mirzaei, M. Saffar-Avval, Enhancement of convec412 tion heat transfer using EHD conduction method, Exper${ }_{413}$ imental Thermal and Fluid Science 93 (2018) 108-118.

[5] T. Persoons, T. Saenen, T. Van Oevelen, M. Baelmans, Effect of Flow Pulsation on the Heat Transfer Performance of a Minichannel Heat Sink, Journal of Heat Transfer 134 (9) (2012) 091702 (7 pp.). doi:10.1115/1.4006485.

[6] G. J. Brereton, Y. Jiang, Convective heat transfer in unsteady laminar parallel flows, Physics of Fluids 18 (10) (2006) 103602. doi:10.1063/1.2359742.

[7] R. Blythman, T. Persoons, N. Jeffers, K. P. Nolan, D. B. Murray, Localised dynamics of laminar pulsatile flow in a rectangular channel, International Journal of Heat and Fluid Flow 66 (2017) 8-17. doi:https://doi.org/10.1016/j.ijheatfluidflow.2017.05.006.

[8] R. Blythman, S. Alimohammadi, T. Persoons, N. Jeffers, D. B. Murray, Parametric analysis of laminar pulsating flow in a rectangular channel, Heat and Mass Transferdoi:10.1007/s00231-017-2196-z.

[9] R. Blythman, T. Persoons, N. Jeffers, D. B. Murray, Heat transfer of laminar pulsating flow in a rectangular channel, Interna- 
tional Journal of Heat and Mass Transfer 128 (2019) 279-289. doi:https://doi.org/10.1016/j.ijheatmasstransfer.2018.08.109.

[10] R. Blythman, T. Persoons, N. Jeffers, D. B. Murray, Effect of oscillation frequency on wall shear stress and pressure drop in a rectangular channel for heat transfer applications, Journal of Physics: Conference Series 745 (3) (2016) 32044.

[11] G. G. Stokes, On the effect of the internal friction of fluids on the motion of pendulums, Transactions of the Cambridge Philosophical Society 9 (1851) 8 .

[12] J. R. Womersley, Method for the calculation of velocity, rate of flow and viscous drag in arteries when the pressure gradient is known, The Journal of Physiology 127 (3) (1955) 553-563. doi:doi:10.1113/jphysiol.1955.sp005276.

[13] E. B. Denison, W. H. Stevenson, Oscillatory Flow Measurements with a Directionally Sensitive Laser Velocimeter, Review of Scientific Instruments 41 (10) (1970) 1475-1478. doi:10.1063/1.1684313.

[14] M. Clamen, P. Minton, An experimental investigation of flow in an oscillating pipe, Journal of Fluid Mechanics 81 (3) (2006) 421-431. doi:10.1017/S0022112077002146.

[15] M. Ojha, R. L. Hummel, S. C. Cobbold, K. W. Johnston, Development and evaluation of a high resolution photochromic dye method for pul- 
satile flow studies, Journal of Physics E: Scientific Instruments 21 (10) (1988) 998 .

[16] R. Roslan, M. Abdulhameed, I. Hashim, A. J. Chamkha, Nonsinusoidal waveform effects on heat transfer performance in pulsating pipe flow, Alexandria Engineering Journal 55 (4) (2016) 3309-3319. doi:https://doi.org/10.1016/j.aej.2016.08.012.

[17] S. Ray, B. Ünsal, F. Durst, Ö. Ertunc, O. A. Bayoumi, Mass Flow Rate Controlled Fully Developed Laminar Pulsating Pipe Flows, Journal of Fluids Engineering 127 (3) (2005) 405-418. doi:10.1115/1.1906265.

[18] B. Mehta, S. Khandekar, Local experimental heat transfer of single-phase pulsating laminar flow in a square mini-channel, International Journal of Thermal Sciences 91 (2015) 157-166. doi:https://doi.org/10.1016/j.ijthermalsci.2015.01.008.

[19] J. McEvoy, S. Alimohammadi, T. Persoons, Experimental and Numerical Investigation of Flow Pulsation in Rectangular Mesochannels for High Heat Flux Electronics Cooling, in: C. J. Kähler, R. Hain, S. Scharnowski, T. Fuchs (Eds.), Proceedings of the 5th International Conference on Experimental Fluid Mechanics, 2018, pp. 45-50.

[20] R. Lindken, J. Westerweel, B. Wieneke, Stereoscopic micro particle image velocimetry, Experiments in Fluids 41 (2) (2006) 161-171. doi:10.1007/s00348-006-0154-5. 
1755

1756

1757

1758

1759

1760

1761

1762

1763

1764

1765

1766

1767

1768

1769

1770

1771

1772

1773

1774

1775

1776

1777

1778

1779

1780

1781

1782

1783

1784

1785

1786

1787

1788

1789

1790

1791

1792

473 [21] M. Raffel, C. Willert, S. Wereley, J. Kompenhans, Particle Image Ve$474 \quad$ locimetry, A Practical Guide, 2nd Edition, Springer, 2007. 
Manuscript title: EXPERIMENTAL INVESTIGATION of PULSATION WAVEFORMS IN RECTANGULAR MESOCHANNELS fOR HIGH HEAT FUUX ELECTRONICS COOLING

The authors whose names are listed immediately below certify that they have NO affiliations with or involvement in any organization or entity with any financial interest (such as honoraria; educational grants; participation in speakers' bureaus; membership, employment, consultancies, stock ownership, or other equity interest; and expert testimony or patent-licensing arrangements), or non-financial interest (such as personal or professional relationships, affiliations, knowledge or beliefs) in the subject matter or materials discussed in this manuscript.

Author names:

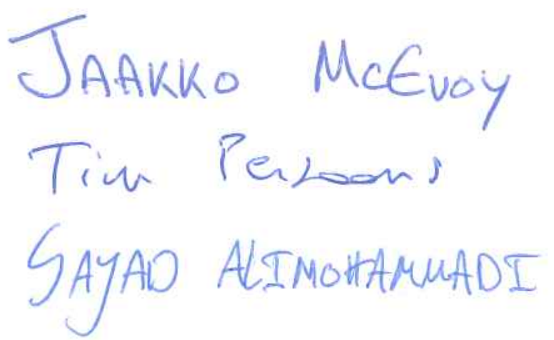

The authors whose names are listed immediately below report the following details of affiliation or involvement in an organization or entity with a financial or non-financial interest in the subject matter or materials discussed in this manuscript. Please specify the nature of the conflict on a separate sheet of paper if the space below is inadequate.

Author names: 
This statement is signed by all the authors to indicate agreement that the above information is true and correct (a photocopy of this form may be used if there are more than 10 authors):

Author's name (typed)

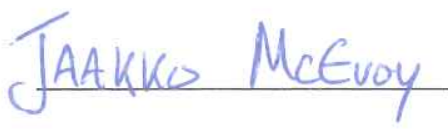

TIM PERSOONS

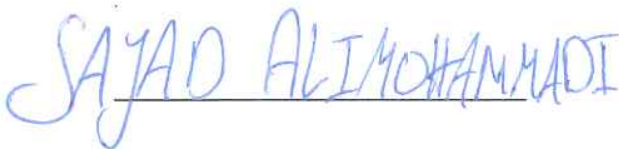

Author's signature
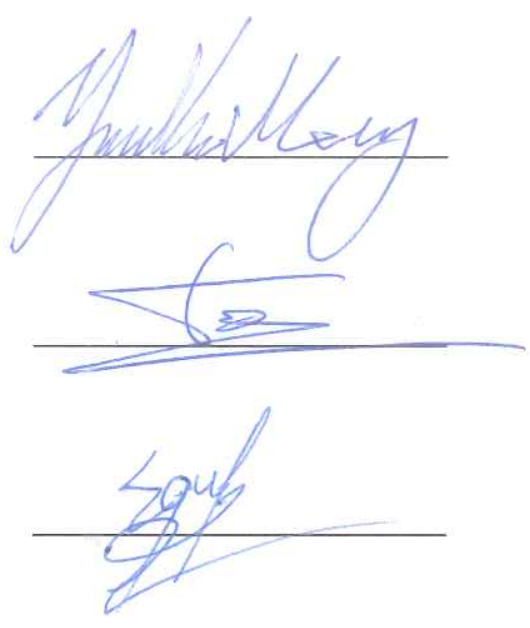

$14 / 12 / 18$

Date

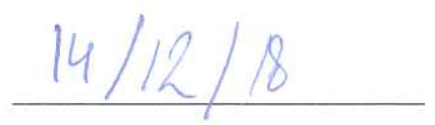

$14 / 12 / 12$

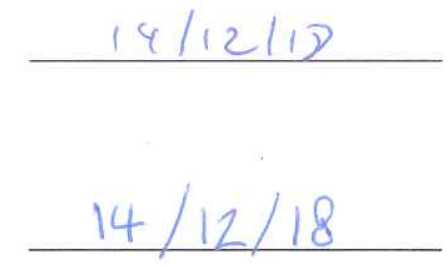

